\title{
O ENIGMA ONTOLÓGICO DA MERCADORIA COMO PONTO DE PARTIDA D'O CAPITAL DE MARX
}

\author{
LEONARDO DA HORA PEREIRA ${ }^{1}$
}

RESUMO: Apesar de ser tido normalmente como um livro de economia, de teoria social ou até mesmo de história, $O$ Capital de Marx possui elementos de grande interesse filosófico. Se adotarmos esse último ponto de vista, torna-se inevitável uma abordagem do primeiro capítulo desta obra, na medida em que ele introduz uma tese curiosa, algo como um enigma ontológico: como algo pode existir de dois modos diferentes, concomitantes e relacionados entre si? Pois esse é o caso da mercadoria, analisada por Marx neste primeiro capítulo. Neste artigo, iremos propor uma leitura deste capítulo com vistas a esclarecer este modo dúplice de existência da mercadoria. Esta tentativa de esclarecimento é a nosso ver relevante, tendo em vista que tal "qüiproquó ontológico" já suscitou inúmeras controvérsias e tal enigma é extremamente importante para a compreensão do resto da obra e da própria dinâmica capitalista, tal como pensada por Marx; não à toa, a explicação do modo de ser da forma-mercadoria se encontra logo no começo do Capital.

PALAVRAS-CHAVE: Marx; mercadoria; capital; ontologia

ABSTRACT: Although it is usually taken as a book of economics, social theory or even history, Marx's Capital has elements of great philosophical interest. If we adopt this last point of view, it becomes inevitable to approach the first chapter of this work, insofar as it introduces a curious thesis, something like an ontological enigma: how something can exist in two different, concomitant and related ways? This is exactly the case of the commodity, analyzed by Marx in this first chapter. In this article, we will propose a reading of this chapter in order to clarify this dual mode of existence of the commodity. This attempt to elucidate is relevant, since such an ontological puzzle has already aroused numerous controversies, and such an enigma is extremely important for the understanding of the rest of the work and of the capitalist dynamics itself.

KEYWORDS: Marx; commodity; capital; ontology

\section{A mercadoria como ponto de partida do Capital}

Apesar de ser tido normalmente como um livro de economia, de teoria social ou até mesmo de história, O Capital de Marx possui elementos de grande interesse filosófico. Se adotarmos esse último ponto de vista, torna-se inevitável uma abordagem do primeiro capítulo desta obra,

\footnotetext{
${ }^{1}$ Professor do Departamento de Filosofia da Universidade Federal da Bahia (UFBA). Pesquisador associado do Laboratório Sophiapol da Universidade de Paris-Nanterre. Doutor em Filosofia pela Université Paris Nanterre. Email: leonardojorgehp@gmail.com.
} 
na medida em que ele introduz uma tese curiosa, uma espécie de enigma ontológico: como algo pode existir de dois modos diferentes, concomitantes e relacionados entre si? Pois esse é o caso da mercadoria, analisada por Marx neste primeiro capítulo. Neste artigo, iremos propor uma leitura deste capítulo com vistas a esclarecer este modo dúplice de existência da mercadoria. Esta tentativa de esclarecimento é a nosso ver relevante, tendo em vista que tal "qüiproquó ontológico" já suscitou inúmeras controvérsias e tal enigma é extremamente importante para a compreensão do resto da obra e da própria dinâmica capitalista, tal como pensada por Marx; não à toa, a explicação do modo de ser da forma-mercadoria se encontra logo no começo do Capital.

O começo do Capital já deu origem a muito debate e interpretação. De fato, a escolha metodológica de Marx é surpreendente, no sentido de que não começa com uma definição de capital (apesar do título do livro), mas com uma análise da mercadoria. No entanto, a primeira sentença do primeiro capítulo confirma que se trata, desde o início, do modo de produção capitalista: "A riqueza das sociedades em que domina o modo de produção capitalista aparece como uma 'imensa coleção de mercadorias' e a mercadoria individual como sua forma elementar" (MARX, 1996, p. 165; MEW 23, p. 49)2. Mas por que as mercadorias?

Marx começa com a análise da mercadoria individual porque esta constitui a forma elementar da riqueza das sociedades capitalistas. Naquele que é chamado de "capítulo VI inédito do Capital", Marx completa essa primeira resposta enfatizando a complexidade da relação que se estabelece entre mercadoria e capital:

\begin{abstract}
Se, ao contrario, consideramos as sociedades de produção capitalista desenvolvida (die Gesellschaften entwickelter capitalistischer Production), a mercadoria aparece tanto na condição de premissa (condição de existência) elementar e constante do capital, como, por outra parte, enquanto resultado imediato do processo capitalista de produção. Mercadoria e dinheiro são, ambos, premissas elementares do capital, mas apenas sob certas condições se desenvolvem até chegar a capital. A formação do capital não pode dar-se a não ser com base na circulação de mercadorias (que inclui a circulação monetária), isto é, em uma fase dada, e desenvolvida até certo ponto, do comércio; ao passo que, inversamente, a produção e circulação de mercadorias de nenhum modo pressupõem para sua existência o modo capitalista de produção (...) De outro lado, apenas sobre a base da produção capitalista a mercadoria converte-se em forma universal do produto, todo produto deve adotar a forma da mercadoria (MARX, 1978, p. 97-8; MEGA II/4.1, p. 27; tradução modificada).
\end{abstract}

Marx mostra, então, que o capital tanto pressupõe a forma-mercadoria e, mais geralmente, a circulação comercial e monetária, como desenvolve e universaliza essa forma. Por outro lado, a

\footnotetext{
${ }^{2}$ Citaremos sempre as traduções brasileiras das obras de Marx acompanhadas do volume correspondente à edição original alemã, seja a edição Marx Engels Werke (MEW), seja a Marx Engels Gesamtausgabe (MEGA), Dietz, Berlin.
} 
mercadoria existe em sociedades pré-capitalistas, portanto esta forma não pressupõe o modo de produção capitalista. No entanto, a perspectiva adotada desde o início do primeiro capítulo, a da mercadoria como a forma elementar (e portanto universal) da riqueza social, é uma característica que só se torna efetiva nas sociedades capitalistas. Ou seja, mesmo admitindo que a mercadoria e a circulação mercantil existem antes do modo de produção capitalista, a primeira seção (incluindo o primeiro capítulo) do Capital já diz respeito a este último.

A questão que surge então é: por que o capital pressupõe a mercadoria, em outras palavras, porque ela é seu ponto de partida? Da mesma forma, pode-se igualmente perguntar por que o modo de produção capitalista é aquele que universaliza a forma da mercadoria. Marx contudo não responde a essas perguntas imediatamente. Ele desenvolve toda a primeira seção do Capital analisando exclusivamente a forma-mercadoria e suas derivações, o que leva à forma-dinheiro. Em que consiste essa análise? Quais são os seus pontos chave? Com efeito, o início do Capital é marcado pela introdução de uma ontologia muito particular, uma ontologia do duplo caráter ou duplo modo de ser das mercadorias, concreto e abstrato. Se Marx escolhe começar sua obra-prima por essa demarcação, é que isso deve ser, como pretendemos mostrar, importante para o resto da análise $\mathrm{e}^{3}$.

\section{A duplicidade ontológica da mercadoria}

A mercadoria é, antes de tudo, um objeto externo, uma coisa, marcada desta forma por um modo de ser bastante banal, empírico, material. É uma coisa útil que satisfaz às necessidades humanas (variáveis historicamente) graças às suas próprias qualidades materiais. Essa materialidade é muito diversa, rica, múltipla e pode, portanto, ser útil de acordo com vários aspectos diferentes. Descobrir esses diversos aspectos e, portanto, os múltiplos modos de usar as coisas é um ato histórico. Essa utilidade da mercadoria faz dela um valor de uso, mas, como Marx observa, "essa utilidade, porém, não paira no ar. Determinada pelas propriedades do corpo da mercadoria, ela não existe sem o mesmo. O corpo da mercadoria mesmo, como ferro, trigo, diamante etc. é, portanto, um valor de uso ou bem" (MARX, 1996, p. 166; MEW 23, p. 50). Além disso, em Para a Crítica da Economia Política, Marx observa que "esse modo de ser (Dasein) da mercadoria como um valor de uso coincide com sua existência natural palpável" (MARX, 1985, p. 135; MEW 13, p. 15). Cada valor de uso corresponde não só a qualidades particulares, mas também a uma certa maneira de medir sua quantidade: "Segundo sua propriedade natural, diversos valores de uso possuem diferentes medidas, como fanga de trigo, resma de papel, vara de tecido" (MARX, 1985, p. 135; MEW 13, p. 15).

\footnotetext{
${ }^{3}$ É bastante conhecido o conselho de Althusser (1980), para os leitores iniciantes, de pular toda a primeira seção do Capital e ir diretamente para a segunda seção. Acreditamos, contudo, que a compreensão dessa primeira seção é essencial para as seções subseqüentes.
} 
Compreender o valor de uso não suscita muitos problemas. Ele diz respeito à utilidade prática dos produtos, seu uso ou consumo. No entanto, o valor de uso não é realmente um traço que distingue a forma social da mercadoria, já que "os valores de uso constituem o conteúdo material da riqueza, qualquer que seja a forma social desta" (MARX, 1996, p. 166; MEW 23, p. 50). É por isso que "não se pode comprovar pelo gosto do trigo quem o cultivou, servo russo, pequeno produtor francês ou capitalista inglês" (MEW, 1985, p. 135; MEW 13, p. 16. Tradução modificada). Isto é, ainda que seja objeto de necessidades sociais, e esteja, por isso, sempre em contexto social, o valor de uso, per se, não expressa nenhuma relação social de produção.

Por outro lado, a forma social examinada carrega um outro tipo de valor, o valor de troca. Este aparece primeiro como a proporção quantitativa ou proporção em que os valores de uso de uma determinada espécie são trocados por valores de uso de outra espécie. O valor de troca caracteriza melhor a differentia specifica da forma-mercadoria na medida em que ela tem a ver diretamente com o comércio, o mercado, a troca e a circulação de produtos. Isso não exclui o valor de uso, muito pelo contrário, porque a troca e o comércio dizem respeito a produtos úteis.

Qual é o modo de ser do valor de troca? Na realidade, uma determinada mercadoria pode ser trocada por várias mercadorias em diferentes proporções, de modo que ela possui múltiplos valores de troca. Além disso, esses múltiplos valores de troca referentes ao mesmo produto são substituíveis um pelo outro. Segue-se que os valores de troca da mesma mercadoria expressam algo igual, do qual eles são apenas o modo de expressão, a forma fenomênica de um conteúdo dissociável deles (MARX, 1996, p. 167; MEW 23, p. 51).

Assim, numa relação de troca entre duas mercadorias, um dado quantum da primeira mercadoria é colocado como igual a um dado quantum da segunda mercadoria, como no exemplo de Marx, 1 quarter de trigo $=$ um quintal de ferro. Esta equação diz que há algo comum e de mesma dimensão em duas coisas diferentes: "Ambas são, portanto, iguais a uma terceira, que em si e para si não é nem uma nem outra. Cada uma das duas, enquanto valor de troca, deve, portanto, ser redutível a essa terceira" (MARX, 1996, p. 167; MEW 23, p. 51).

É aqui que a questão ontológica deste segundo modo de ser da mercadoria se torna premente. Porque esse algo comum não pode ser uma propriedade natural desses bens, seja uma propriedade geométrica, física, química ou algo do tipo. Marx lembra que as propriedades naturais das mercadorias só são relevantes na medida em que elas são valores de uso. Mas então, o que constitui esse algo em comum exposto nas relações de troca entre elas? Segundo Marx, "é precisamente a abstração de seus valores de uso (die Abstraktion von ihren Gebrauchswerten) que caracteriza evidentemente a relação de troca das mercadorias. Dentro da mesma um valor de uso vale exatamente tanto como outro qualquer, desde que esteja disponível em proporção adequada" (MARX, 1996, p. 167; MEW 23, p. 51-2). 
Vemos, assim, a introdução de um mecanismo muito particular na relação de troca, o da abstração. Trata-se do começo no Capital de uma análise ontológica de um modo de ser abstrato das mercadorias, o qual logo se revelará como efeito de um tipo de prática social.

Com efeito, a realidade da mercadoria, sua differentia specifica, é muito marcada por essa dimensão abstrata. Se, como valores de uso, os bens são de qualidade diferente, como valores de troca eles são apenas de quantidades diferentes. No entanto, se ignorarmos o valor do uso da mercadoria, de seu corpo, o que resta? Segundo Marx, resta apenas uma propriedade: a de ser produto do trabalho. Além disso, se fizermos abstração de todos os componentes corporais e caracteres sensíveis das mercadorias, nós abstraímos ao mesmo tempo as características úteis e peculiares dos trabalhos presentes nesses produtos, e da mesma forma, das diferentes formas concretas destes trabalhos. Ou seja, é o próprio trabalho que se reduz a trabalho humano abstrato:

Não restou deles a não ser a mesma objetividade fantasmagórica, uma simples gelatina
de trabalho humano indiferenciado, isto é, do dispêndio de força de trabalho humano,
sem consideração pela forma como foi despendida. O que essas coisas ainda
representam é apenas que em sua produção foi despendida força de trabalho humano,
foi acumulado trabalho humano. Como cristalizações dessa substância social comum
a todas elas, são elas valores - valores mercantis (MARX, 1996, p. 168; MEW 23,
p. 52).

Ao estabelecer a categoria de trabalho abstrato, Marx estabelece simultaneamente a distinção entre valor e valor de troca. Valor é o que há em comum, o que é exposto na relação de troca ou nos diferentes valores de troca da mercadoria. $\mathrm{O}$ valor de troca é apenas seu modo de expressão ou sua forma fenomênica necessária.

Portanto, um produto dotado de valor de uso só possui valor na medida em que é uma objetivação de trabalho humano abstrato. Como a magnitude de seu valor é medida? Pelo quantum de trabalho, isto é, pelo tempo de trabalho contido nos bens. Mas então, isso significa que quanto mais tempo um indivíduo leva para fabricar uma mercadoria, mais valioso ela será? Vimos no início que a mercadoria no modo de produção capitalista se torna a forma universal de riqueza. O que isso significa? Isso significa que a universalização da mercadoria corresponde à universalização da troca, do comércio, enfim, do mercado como modo de coordenação e distribuição das riquezas. Portanto, o mercado deve assegurar a reprodução material da sociedade através da alocação de trabalho social nos diferentes ramos de produção, isto é, estabelecendo uma divisão social do trabalho. Do contrário, as necessidades sociais não poderiam ser satisfeitas e esse modo de produção baseado no mercado generalizado entraria em colapso. Como o mercado generalizado garante isso? Através da competição entre diferentes produtores de mercadorias e movimentos de valores mercantis (Marx ainda não definiu os preços neste momento de sua exposição). Assim, a produção de cada mercadoria deve adaptar- 
se mais ou menos à média de sua espécie, pois seu valor depende da concorrência em cada ramo. Sendo assim, a magnitude deste valor será determinada pelo tempo de trabalho gasto em média ou socialmente necessário para a produção da mercadoria em questão, e não pelo tempo de trabalho individual.

Ainda que implicitamente ${ }^{4}$, Marx pressupõe isso tudo quanto afirma que:

\begin{abstract}
A força conjunta de trabalho da sociedade, que se apresenta nos valores do mundo das mercadorias, vale aqui como uma única e a mesma força de trabalho do homem, não obstante ela ser composta de inúmeras forças de trabalho individuais. Cada uma dessas forças de trabalho individuais é a mesma força de trabalho do homem como a outra, à medida que possui o caráter de uma força média de trabalho social, e opera como tal força de trabalho socialmente média, contanto que na produção de uma mercadoria não consuma mais que o trabalho em média necessário ou tempo de trabalho socialmente necessário. Tempo de trabalho socialmente necessário é aquele requerido para produzir um valor de uso qualquer, nas condições dadas de produção socialmente normais, e com o grau social médio de habilidade e de intensidade de trabalho (MARX, 1996, p. 168-9; MEW 23, p. 53).
\end{abstract}

A magnitude do valor de uma mercadoria não é, portanto, algo fixo, ela muda com as transformações na força produtiva do trabalho, que depende da habilidade média dos trabalhadores, do desenvolvimento das ciências, da aplicação tecnológica, etc. Por outro lado, a operação de abstração é sempre algo essencial, tão impressionante quanto diária:

Para medir os valores de troca das mercadorias pelo tempo de trabalho contido nelas, os diversos trabalhos devem estar reduzidos a trabalho sem diferenças, uniforme, simples; em breve, a trabalho que é qualitativamente o mesmo, e por isso, se diferencia apenas quantitativamente. Esta redução aparece como uma abstração, mas é uma abstração que é praticada diariamente no processo social de produção (MARX, 1985, p. 137, MEW 13, p. 18).

A mercadoria aparece dessa forma como uma coisa "bífida" (Zwieschlächtiges), valor de uso e valor de troca. Da mesma forma, o trabalho contido na mercadoria tem um duplo caráter, representado pelo par trabalho concreto e trabalho abstrato:

Todo trabalho é, por um lado, dispêndio de força de trabalho do homem no sentido fisiológico, e nessa qualidade de trabalho humano igual ou trabalho humano abstrato gera o valor da mercadoria. Todo trabalho é, por outro lado, dispêndio de força de trabalho do homem sob forma especificamente adequada a um fim, e nessa qualidade de trabalho concreto útil produz valores de uso (MARX, 1996, p. 175; MEW 23, p. 61).

\footnotetext{
${ }^{4}$ Em seu comentário sobre o Capital, David Harvey faz esse trabalho de explicitação (Cf. HARVEY, 2010, p. 20). Como vemos, Marx só pode se explicar sobre a mercadoria formulando os caracteres do sistema de mercadorias enquanto lógica da produção.
} 
No modo de produção capitalista, onde a forma-mercadoria se torna universal, o trabalho abstrato corresponde à forma histórica assumida pelo trabalho social nessa sociedade. O duplo caráter do trabalho incorporado na mercadoria reflete, assim, a relação entre o trabalho privado e o trabalho social dos produtores. A propriedade privada dos meios de produção separa os homens, faz do trabalho de cada produtor seu negócio privado. Cada produtor de bens trabalha, em principio, de forma isolada, produzindo para a troca. $\mathrm{O}$ trabalho dos vários trabalhadores não é coordenado ao nível de toda a sociedade. Por outro lado, a divisão social do trabalho reflete a existência de uma infinidade de ligações entre produtores que trabalham um para o outro. Esta divisão é uma condição de existência da produção mercantil-capitalista. Portanto, o trabalho do produtor isolado é, no fundo, trabalho social; ele constitui uma parcela do trabalho da sociedade como um todo. As mercadorias, que são os produtos de várias formas de trabalho privado concreto, são ao mesmo tempo produtos do trabalho humano em geral, do trabalho abstrato, na medida em que esta diferença qualitativa entre os diferentes trabalhos úteis se articula em uma divisão social do trabalho.

Mas se a divisão social do trabalho é condição de existência para a produção de mercadorias, o inverso não é verdadeiro. Como exemplifica Marx:

(...) $\mathrm{Na}$ antiga comunidade hindu o trabalho é socialmente dividido sem que os produtos se tornem mercadorias. Ou, um exemplo mais próximo, em cada fábrica o trabalho é sistematicamente dividido, mas essa divisão não se realiza mediante a troca, pelos trabalhadores, de seus produtos individuais. Apenas produtos de trabalhos privados autônomos e independentes entre si confrontam-se como mercadorias (MARX, 1996, p. 171; MEW 23, p. 57).

O traço característico da produção mercantil é, portanto, que só podem se apresentar face a face como mercadorias aqueles bens e produtos produzidos por trabalhos privados autônomos e independentes entre si. A divisão do trabalho é mediada por uma troca de produtos. Assim, o trabalho dos produtores de mercadorias, enquanto diretamente seus negócios privados, é ao mesmo tempo social.

Por outro lado, deve-se ressaltar que, mesmo que a mercadoria deva ter valor de uso e deva conter trabalho útil concreto para poder ser trocada, é seu outro modo de ser, abstrato, que funda sua especificidade, até porque o trabalho concreto é "uma condição de existência do homem, independente de todas as formas de sociedade, eterna necessidade natural de mediação do metabolismo (Stoffwechsel) entre homem e natureza e, portanto, da vida humana" (MARX, 1996, p. 172; MEW 23, p. 57). Em outras palavras, mesmo que o valor de uso seja a "forma natural banal”" das mercadorias, elas só são mercadorias "devido à sua duplicidade, objetos de uso e simultaneamente portadores de valor. Elas aparecem, por isso, como mercadoria ou 
possuem a forma de mercadoria apenas na medida em que possuem forma dupla (Doppelform), forma natural e forma de valor" (MARX, 1996, p. 176; MEW 23, p. 62).

Essa "duplicidade ontológica" que marca a existência das mercadorias não é isenta de tensões, que podem se revelar verdadeiras contradições. A principal delas se encontra talvez no nível da medição da riqueza. Tal duplicidade produz, com efeito, uma cisão no modo de conceber e medir a riqueza. De um lado, temos a riqueza material, medida pelo quantum de valores de uso produzidos pelo trabalho concreto; de outro, temos a grandeza do valor, que remete ao trabalho abstrato e é medida pelo tempo de trabalho socialmente necessário para a produção de dada mercadoria. No último caso, em oposição ao primeiro, temos um tempo medido abstratamente, pois a forma que a sociabilidade produtiva assume no modo de produção mercantil-capitalista é marcada, como vimos, pelo signo da abstração. Abstrai-se para socializar-se.

Mas onde reside a possível contradição? Já no primeiro capítulo do Capital, Marx menciona uma possibilidade que vai se tornar decisiva para a compreensão do modo como ele vai vislumbrar, segundo certas leituras, o núcleo da crise do modo de produção capitalista ${ }_{2}$ bem como o núcleo da própria possibilidade de sua superação:

\footnotetext{
Um quantum maior de valor de uso representa em si e para si maior riqueza material, dois casacos mais que um. Com dois casacos podem-se vestir duas pessoas, com um casaco, somente uma pessoa etc. Entretanto, à crescente massa de riqueza material pode corresponder um decréscimo simultâneo da grandeza de valor. Esse movimento contraditório origina-se do duplo caráter do trabalho (...) Ao contrário, uma mudança da força produtiva não afeta, em si e para si, de modo algum o trabalho representado no valor. Como a força produtiva pertence à forma concreta útil do trabalho, já não pode esta, naturalmente, afetar o trabalho, tão logo faça-se abstração da sua forma concreta útil. O mesmo trabalho proporciona, portanto, nos mesmos espaços de tempo, sempre a mesma grandeza de valor, qualquer que seja a mudança da força produtiva. Mas ele fornece, no mesmo espaço de tempo, quantidades diferentes de valores de uso; mais, quando a força produtiva sobe, e menos, quando ela cai. A mesma variação da força produtiva, a qual aumenta a fecundidade do trabalho e, portanto, a massa de valores de uso por ela fornecida, diminui, assim, a grandeza de valor dessa massa global aumentada, quando ela encurta a soma do tempo de trabalho necessário à sua produção. E vice-versa (MARX, 1996, p. 175; MEW 23, p. 61).
}

Ou seja, Marx admite a possibilidade, com o aumento da força produtiva mediante aperfeiçoamento tecnológico, de que a riqueza material possa aumentar na mesma proporção que diminui a grandeza de valor dessa massa de valores de uso. Isso porque o modo de medir quantitativamente estas duas formas de riqueza é diferente. Tudo se passa como se tivéssemos "duas realidades" ou "dois mundos" paralelos no modo de produção capitalista - um relacionado ao metabolismo orgânico e material do ser humano com a natureza (cuja magnitude seria representada pela riqueza material) e o outro relacionado a um modo histórico e 
especificamente mercantil-capitalista de garantir a repartição social desse metabolismo (cuja grandeza seria representada pelo valor); tais aspectos distintos podem contudo interagir entre si e mesmo entrar em contradição ${ }^{5}$.

\section{A natureza da objetividade do valor}

Marx insiste, portanto, na duplicidade ontológica, sobre o duplo modo de ser das mercadorias. Todo o começo do Capital gira em torno do estabelecimento desta tese. Podemos, portanto, supor que ela é central para a compreensão marxiana do modo de produção capitalista. O que surpreende nesta ontologia das mercadorias é que Marx reivindica uma objetividade para o valor das mercadorias, ao lado da objetividade sensível de seus corpos. No entanto, na objetividade de seu valor "não se encerra nenhum átomo de matéria natural"; isto é, "podemos virar e revirar uma mercadoria, como queiramos, como coisa de valor ela permanece imperceptível" (MARX, 1996, p. 176; MEW 23, p. 62). O que Marx diz não deixa de ser surpreendente por parte de um homem conhecido por seu materialismo: o valor é imaterial, mas objetivo (Cf. HARVEY, 2010, p. 33). Assim, Marx rejeita a mera ontologia material na determinação do modo de ser do valor. O que então funda essa objetividade?

A resposta de Marx é muito instrutiva. Valendo-se de uma linguagem ontológica pouco mencionada pelos intérpretes do Capital $_{2}$ mas profundamente presente neste primeiro capítulo, ele nos lembra que as mercadorias só têm objetividade de valor na medida em que expressam uma mesma unidade social, representada pelo conceito de trabalho humano abstrato. Sua objetividade de valor é, portanto, puramente social, podendo aparecer apenas na relação social

\footnotetext{
${ }^{5}$ Neste cenário, se a riqueza abstrata (valor) diminui, é a sociabilidade capitalista, fundada no tempo de trabalho, que entra em crise em função do processo de automação e do desenvolvimento tecnológico. Bem entendido, a abundância material permanece de pé e em crescimento, o que entra em crise é apenas o modo capitalista de socializar o trabalho, porque a própria necessidade de trabalho diminui com a aplicação progressiva da ciência e da tecnologia ao processo produtivo. Nos Grundrisse Marx acena com essa possibilidade no por vezes chamado "Fragmento sobre as máquinas" (cujo título na verdade é "Capital fixo e desenvolvimento das forças produtivas da sociedade") (MARX, 2011, p. 926ss; MEGA II/1.2, p. 569ss). Neste caso, ainda que a forma-valor continue pressupondo o tempo de trabalho (direto) para a definição da sua grandeza, esta necessidade de medir a riqueza de acordo com as horas (em média) trabalhadas se torna cada vez menos uma necessidade para a vida humana em sentido amplo, para a fruição dos bens e produtos; isto é, valor (capital) e vida humana tendem a se separar. Um intérprete como Moishe Postone (2003) irá enxergar nessa possibilidade o verdadeiro sentido de emancipação social em Marx. Segundo sua leitura, a real emancipação reside no "fim do trabalho" (e na conseqüente abolição do proletariado), que traria consigo o fim do próprio valor (da riqueza social fundada no tempo de trabalho), e não na "realização" do trabalho e do proletariado, isto é, na construção de uma sociedade de "trabalhadores sem patrão". O reino da liberdade seria efetivamente possível apenas com o fim da necessidade do trabalho direto e com a liberação máxima de tempo livre.
} 
da troca entre mercadorias. A origem de sua objetividade ou modo específico de ser não é, portanto, encontrada em uma ontologia natural ou material, mas, por assim dizer, em uma “ontologia socialmente produzida". Como bem diz Harvey, "o valor é uma relação social e você não pode realmente ver, tocar ou sentir relações sociais diretamente; ainda assim elas têm uma presença objetiva" (HARVEY, 2010, p. 33). A questão é que as relações sociais mercantiscapitalistas possuem a marca da abstração e - insistiremos ainda sobre este ponto mais adiante - se expressam através de coisas.

É nesta explicação social do fenômeno da mercadoria e da relação de troca que reside a grande contribuição de Marx, como recordou Jacques Rancière: "Em outras palavras, a equação $\mathrm{x}$ mercadorias $\mathrm{A}=\mathrm{y}$ mercadorias $\mathrm{B}$, é, como vimos, uma equação impossível. O que Marx vai fazer e que o distingue radicalmente da economia clássica, é a teoria da possibilidade dessa equação impossível. Na falta dessa teoria, a economia clássica não pode conceber o sistema no qual a produção capitalista é articulada" (RANCIERE, 2014, p. 121).

É, portanto, uma relação social que funda a objetividade do valor da mercadoria; trata-se de uma sociabilidade que se expressa nas coisas, nas mercadorias, e lhes atribui outro modo de ser ao lado de sua forma natural, sensível ou material: "As condições de trabalho que põem valor de troca, tais como resulta da análise do valor de troca, são determinações sociais do trabalho, ou determinações de trabalho social, mas não pura e simplesmente social, mas de um modo particular: é um tipo específico de sociabilidade (Gesellschaftlichkeit)" (MARX, 1985, p. 138; MEW 13, p. 19. Tradução modificada).

Nos Grundrisse, Marx explica a natureza da transformação qualitativa (e não apenas quantitativa) que a mercadoria deve sofrer (primeiro na cabeça dos atores sociais, na representação) para ser trocada, o que torna claro o caráter puramente social (enquanto expressão de relações de produção) desse modo de ser, que na verdade corresponde a um modo de aparecer socialmente objetivo:

Os produtos (ou atividades) trocam-se somente como mercadorias; as mercadorias, na própria troca, existem só como valores; somente enquanto tais elas se comparam. Para determinar o peso de pão que posso trocar por uma vara de linho, primeiro faço a vara de linho $=$ seu valor de troca, i.e., $=1 / x$ tempo de trabalho. Da mesma forma, faço a libra de pão $=$ seu valor de troca $=1 / x$, ou $2 / x$, etc. tempo de trabalho. Faço cada uma das mercadorias = um terceiro termo; i.e., desiguais de si mesmas. Esse terceiro termo, diferente de ambas, uma vez que expressa uma relação, existe de início na cabeça, na representação, da única maneira, enfim, que relações podem ser pensadas se têm de ser fixadas diferentemente dos termos [Subjekten] em que se relacionam. Quando um produto (atividade) devém valor de troca, é transformado não só em uma relação quantitativa determinada, em uma proporção - a saber, em um número que expressa qual quantidade de outras mercadorias é igual a ele, seu equivalente, ou em qual relação é o equivalente de outras mercadorias -, mas deve ao mesmo tempo ser transformado qualitativamente, ser convertido em um outro elemento, para que ambas 
as mercadorias devenham magnitudes concretas com a mesma unidade, logo, devenham comensuráveis (MARX, 2011, p. 137-8; MEGA II/1.1, p. 77-8).

Marx começou com o valor de troca de mercadorias para estabelecer seu valor com base no trabalho abstrato. Agora, a partir dessa observação sobre a origem social e relacional da objetividade do valor, ele retorna ao valor de troca enquanto forma fenomênica do valor. $\mathrm{O}$ desafio é compreender "a expressão de valor" a partir da "relação de valor" que é estabelecida entre as mercadorias. Ou seja, o valor, sendo objetivo (existente), mas imaterial e relacional, necessita de um modo de aparição, uma forma fenomênica, um meio de expressão tangível. Marx mostrará que a mercadoria como valor de troca e, de uma maneira mais desenvolvida, como moeda ou dinheiro, é justamente este modo: "Toda pessoa sabe, ainda que não saiba mais do que isso, que as mercadorias possuem uma forma comum de valor, que contrasta de maneira muito marcante com a heterogeneidade das formas naturais que apresentam seus valores de uso — a forma dinheiro" (MARX, 1996, p. 176; MEW 23, p. 62).

Trata-se, portanto, de mostrar a gênese da forma-dinheiro. Não obstante, se o valor não é material, se ele não existe no corpo da mercadoria, qual é exatamente sua forma de expressão sensível? Como conceber a forma tangível de algo abstrato? Não temos uma contradição nisso? O que equivale a perguntar: qual é o segredo do dinheiro?

\section{O social e as coisas}

A seguinte passagem dos Grundrisse mostra bem o sentido da gênese do dinheiro: materializar um modo de ser abstrato na realidade material no momento da troca efetiva, já que até então a abstração era realizada, como vimos, na cabeça, na representação. É como se o abstrato se encarnasse no concreto:

Para uma simples comparação - avaliação dos produtos -, para a determinação ideal de seu valor, é suficiente realizar mentalmente tal transformação (uma transformação em que o produto existe simplesmente como expressão de relações de produção quantitativas). Na comparação das mercadorias, essa abstração é suficiente; na troca efetiva, a abstração deve ser, por sua vez, objetivada, simbolizada, realizada por um signo. Essa necessidade se dá [porque]: 1) como já dissemos, as mercadorias em troca são ambas transformadas na cabeça em relações de mesma grandeza, em valores de troca, e são desse modo avaliadas uma em relação à outra. No entanto, caso tenham de ser efetivamente trocadas, as suas propriedades naturais entram em contradição com sua determinação como valores de troca e simples números concretos. Elas não são divisíveis à vontade etc.; 2) na troca efetiva, mercadorias particulares são constantemente trocadas por mercadorias particulares e a permutabilidade de cada mercadoria, bem como a relação em que é permutável, depende de condições locais, temporais etc. Mas a transformação da mercadoria em valor de troca não a equipara a uma outra mercadoria particular, mas a expressa como equivalente, expressa sua relação de permutabilidade com todas as outras mercadorias (...) Portanto, para 
realizar a mercadoria de um só golpe em valor de troca e lhe conferir a eficiência universal do valor de troca, não é suficiente a troca por uma mercadoria particular. A mercadoria deve ser trocada por uma terceira coisa que, por sua vez, não seja ela mesma uma mercadoria particular, mas o símbolo da mercadoria como mercadoria, o próprio valor de troca da mercadoria; portanto, que represente, digamos, o tempo de trabalho enquanto tal, digamos, um pedaço de papel ou de couro que represente uma parte alíquota de tempo de trabalho. (Um tal símbolo presume o reconhecimento universal; só pode ser um símbolo social; expressa de fato apenas uma relação social) (MARX, 2011, p. 138; MEGA II/1.1, p. 78).

Como se vê, as propriedades ontológicas naturais da mercadoria entram em contradição com as propriedades ontológicas abstratas do valor, como por exemplo o de ser uma substância divisível à vontade, a homogeneidade e permutabilidade universal, etc. Portanto, para que na troca efetiva todas estas propriedades ontológicas venham à tona, é necessária_uma "terceira coisa", que não seja uma mercadoria particular mas que seja a representação ou o signo de uma relação social abstrata, de um tempo de trabalho abstrato. O dinheiro é justamente esse operador ontológico fundamental que permite assim que dois modos de ser radicalmente distintos possam interagir e se interpenetrar na sociabilidade mercantil-capitalista.

Com isso, compreendemos o sentido ou a função da forma-dinheiro, mas ainda não é claro como ela se torna possível. Como uma "terceira coisa" pode representar, enquanto tal, uma relação social, uma permutabilidade universal, enfim, propriedades ontológicas abstratas?

No Capital, Marx tenta desnudar este segredo começando a sua análise da forma-valor (valor de troca) com uma relação de troca simples, do tipo: $\mathrm{x}$ mercadoria $\mathrm{A}=\mathrm{y}$ mercadoria $\mathrm{B}$, no sentido de $\mathrm{X}$ mercadoria $\mathrm{A}$ vale y mercadoria $\mathrm{B}$, pois o segredo de toda forma-valor residiria nesta relação simples. A essência da tese de Marx sobre esse ponto consiste em mostrar que a relação de valor ou de troca não é reflexiva, isto é, não é redutível a uma igualdade simples, já que não há nenhum sentido em trocar um casaco por um casaco idêntico. Esta relação supõe, portanto, dois pólos distintos. Esta forma simples expressa a condição mais geral da expressão de valor, ou seja, a bipolaridade funcional dos dois pólos. No seguinte exemplo ${ }_{2}$ "20 metros de tecido valem um casaco", o primeiro elemento ${ }_{2}$ "20 metros de tecido", exprime o seu valor no outro, "um casaco". Marx chama o primeiro pólo de forma-valor relativa e o segundo de formaequivalente. Os dois pólos não possuem apenas o mesmo valor em termos quantitativos. A mercadoria A (forma-valor relativa) exprime seu valor por meio do valor de uso da mercadoria B (forma-equivalente).

Vimos que a objetividade do valor de uma mercadoria não está em seu corpo, em seu valor de uso. Da mesma forma, vimos que essa objetividade só aparece na relação entre duas mercadorias. Agora, Marx mostra que o valor de uma mercadoria é expresso no valor de uso de 
outra mercadoria. Isso não nos traz simplesmente de volta a uma mera ontologia materialista simplória?

Esse não é exatamente o caso, porque essa expressão de valor de uma mercadoria na outra pressupõe que esses dois bens sejam qualitativamente iguais: "Perde-se de vista que as grandezas de coisas diferentes tornam-se quantitativamente comparáveis só depois de reduzidas à mesma unidade" (MARX, 1996, p. 178; MEW 23, p. 64). Subentende-se portanto em nosso exemplo que o tecido e o casaco são coisas da mesma natureza, uma natureza necessariamente abstrata. Por outro lado, apenas o valor do tecido é expresso, o casaco é tomado como uma forma de existência do valor, coisa-valor, porque é apenas como tal que é a mesma coisa que o tecido. Por outro lado, o valor do tecido adquire uma expressão autônoma, uma vez que é apenas como um valor que ele pode ser identificado e comparado ao casaco. É como se a relação com outra mercadoria provocasse a exteriorização do valor contido na mercadoria:

\footnotetext{
Digamos: como valores, as mercadorias são meras gelatinas de trabalho humano, então a nossa análise reduz as mesmas à abstração de valor, sem dar-lhes, porém, qualquer forma de valor diferente de suas formas naturais. A coisa é diferente na relação de valor de uma mercadoria à outra. Seu caráter de valor revela-se aqui por meio de sua própria relação à outra mercadoria (MARX, 1996, p. 179 ; MEW 23, p. $65)$.
}

Por que a relação de valor ou de troca produz essa expressão de valor, uma forma-valor distinta da forma natural da mercadoria? Porque é a troca que produz o mecanismo de abstração, é a troca que nos empurra para equalizar as mercadorias e, assim, a abstrair seus valores de uso, destacando seu caráter de valor e o trabalho abstrato nele contido:

\footnotetext{
Ao equiparar-se, por exemplo, o casaco, como coisa de valor, ao linho, é equiparado o trabalho inserido no primeiro com o trabalho contido neste último. Na verdade, a alfaiataria que faz o casaco é uma espécie de trabalho concreto diferente da tecelagem que faz o linho. Porém, a equiparação com a tecelagem reduz a alfaiataria realmente àquilo em que ambos são iguais, a seu caráter comum de trabalho humano (MARX, 1996, p. 179 ; MEW 23, p. 65)
}

A relação de troca engendra, assim, um "olhar" socialmente produzido que nos permite ver a coisa, o valor de uso, diferentemente, de acordo com outros traços e propriedades ontológicas. Certamente, na produção do casaco, havia de fato um gasto de força de trabalho humana, na forma de confecção - nesse sentido, uma despesa fisiológica de força de trabalho humano. Há, portanto, no casaco trabalho humano acumulado. No entanto, por exemplo, nada garante que isso corresponda exatamente ao tempo de trabalho socialmente necessário. Como ressalta Rancière: 
A coisidade (choséité) das mercadorias é uma coisidade social, sua objetividade, uma objetividade de valor (...) O que toma a forma de uma coisa não é o trabalho enquanto atividade de um sujeito, mas sim o caráter social do trabalho. E o trabalho humano de que estamos falando aqui não é o trabalho de qualquer subjetividade constituinte. Ele carrega a marca de uma estrutura social determinada (RANCIÈRE, 2014, p. 122).

No âmbito ontológico estritamente sensível e material, a mercadoria é produto de um trabalho particular, concreto e privado, realizado ao longo de um tempo igualmente concreto, vivido e particular. Ela não é, portanto, fruto de trabalho humano em geral, abstrato; este último constitui uma realidade puramente social, como temos insistido, e esta realidade social condiciona o olhar dos agentes sociais, dos portadores dessa forma de sociabilidade mercantilcapitalista. Neste sentido, o socius capitalista constitui o que é visível, na medida em que se exprime por meio de coisas materiais.

O ponto de vista social condicionado pela produção/circulação mercantil-capitalista consiste em ver em coisas (mercadorias) a figura ou a substância de um trabalho humano em geral ou abstrato, isto é, o valor. A esse respeito, o casaco é "portador de valor". Na relação de troca com o tecido (linho), ele vale apenas sob esse aspecto: como um valor incorporado, como um corpo de valor.

Bem entendido, no modo de produção capitalista estamos lidando com uma objetividade que é de fato socialmente produzida - no sentido de que é somente dentro da relação social de troca que este ponto de vista abstrato se torna, em termos práticos (e não apenas teoricamente), possível e efetivo. Ou seja, temos uma objetividade que é imaterial, que não se encontra na constituição natural das mercadorias. No entanto, é importante ressaltar que essa objetividade do valor existe realmente em termos sociais; não se trata de uma mera invenção arbitrária ou mesmo de uma simples convenção. O fato de não ser uma objetividade material não significa que não tenha nenhuma relação com a materialidade e a concretude das atividades produtivas. Não há trabalho abstrato sem trabalho concreto; ambos constituem os dois aspectos de uma mesma realidade produtiva e social, marcada por um determinado mecanismo de socialização do trabalho e da produção. A rigor, o valor não é a invenção de outra realidade à parte, mas a expressão de uma realidade social em coisas materiais.

Valor, trabalho abstrato e sua medida em tempo de trabalho socialmente necessário, todas essas abstrações estão assentadas em uma produção real, concreta, onde houve de fato um gasto fisiológico de trabalho, mas na forma de trabalhos privados, particulares, que só se socializam através da troca mercantil e cuja magnitude corresponde (em valor) a uma certa média social (o tempo de trabalho socialmente necessário). O modo de ser de valor dos produtos desses trabalhos privados e concretos é, portanto, puramente social, embora esse social reflita mais ou 
menos (em média) uma realidade material (fragmentada em unidades formalmente independentes) de gasto fisiológico de trabalhos específicos e distintos entre si. Como vimos, a abstração, a metamorfose qualitativa, consiste em considerar este conjunto de trabalhos privados como trabalho humano idêntico, como gasto da mesma força de trabalho humana em geral: uma base de produção fragmentada corresponde a uma sociabilidade por abstração que considera as coisas apenas através de sua média social. $\mathrm{O}$ trabalho abstrato é portanto a expressão da socialização e integração dos diferentes trabalhos concretos e não a invenção de outra realidade.

Nesta passagem, Marx critica justamente aqueles que tomam o dinheiro como um puro signo arbitrário, mostrando que seu valor repousa sobre uma base social material:

\begin{abstract}
O processo de troca dá à mercadoria, a qual é por ele transformada em dinheiro, não o seu valor, porém sua forma-valor (Wertform) específica. A confusão entre essas duas determinações levou a considerar o valor do ouro e da prata como sendo imaginário. Podendo o dinheiro ser substituído, em certas funções, por meros signos dele mesmo, surgiu o outro erro, que ele seja mero signo. Por outro lado, essa noção implicava vislumbrar que a forma dinheiro da coisa é externa a ela mesma e mera forma de manifestação de relações humanas ocultas atrás dela. Nesse sentido, cada mercadoria seria um signo, pois, como valor, é apenas um invólucro reificado do trabalho humano nela despendido. Mas, ao considerar os caracteres sociais que as coisas ou os caracteres reificados que as determinações sociais do trabalho recebem, com base em determinado modo de produção, como meros signos, eles passam, ao mesmo tempo, a ser explicados como produto arbitrário da reflexão dos homens (...) Sabe-se que ouro é dinheiro, sendo, portanto, diretamente permutável com todas as mercadorias. Mas nem por isso sabe-se quanto valem, por exemplo, 10 libras de ouro. Como qualquer outra mercadoria, o dinheiro pode expressar sua própria grandeza de valor apenas relativamente em outras mercadorias. Seu próprio valor é determinado pelo tempo de trabalho necessário a sua produção e se expressa naquele quantum de qualquer outra mercadoria em que está cristalizado o mesmo tempo de trabalho (MARX, 1996, p. 214-6; MEW 23, p. 105-6).
\end{abstract}

Com a forma equivalente, temos assim um fato bastante paradoxal: o valor de uso tornase a forma fenomênica, de aparição, de seu oposto, do valor. Ou seja, a forma natural da mercadoria se torna forma-valor. Mas essa forma natural torna-se então apenas o suporte para a realização de um ponto de vista abstrato, estabelecido apenas na relação de troca. Quando a abstração diz respeito a trocas reais, precisamos de um suporte natural, o corpo de outra mercadoria, para expressar o valor de uma mercadoria.

A escolha do suporte não é, no entanto, aleatória. Não é qualquer pedaço de matéria que pode expressar valor. Esse outro corpo, esse suporte, também deve conter valor, o que implica (i) ser fruto de um determinado trabalho humano e (ii) ser objeto de uma demanda social efetiva (trabalho útil). Marx tenta explicar isso através de um exemplo físico: 


\begin{abstract}
Que nos ilustre isso o exemplo de uma medida que se aplica aos corpos de mercadorias como corpos de mercadorias, isto é, como valores de uso. Um pão de açúcar sendo corpo é pesado e tem, portanto, peso, porém não se pode ver ou servir o peso de nenhum pão de açúcar. Tomemos então pedaços diferentes de ferro, cujo peso foi determinado antes. Considerada em si, a forma do ferro é tão pouco forma de manifestação do peso quanto a do pão de açúcar. Contudo, para expressar o pão de açúcar como peso, nós o colocamos numa relação de peso com o ferro. Nessa relação o ferro figura como um corpo, que nada representa além de peso. Quantidades de ferro servem, portanto, como medida de peso do açúcar e representam perante o corpo do açúcar mera figuração do peso, forma de manifestação de peso. $O$ ferro desempenha esse papel apenas dentro dessa relação, na qual entra o açúcar ou qualquer outro corpo, cujo peso deve ser encontrado. Caso ambas as coisas não fossem pesadas, não poderiam entrar nessa relação, e um não poderia sentir, portanto, de expressão do peso do outro. Lancemos ambos sobre uma balança, e veremos de fato que eles enquanto peso são o mesmo e, portanto, em proporção determinada, são do mesmo peso. Como medida de peso, o ferro representa em confronto com o pão de açúcar apenas peso, e assim, em nossa expressão de valor, o corpo do casaco representa em relação ao linho apenas valor (MARX, 1996, p. 184-5; MEW 23, p. 71. Grifo nosso).
\end{abstract}

Ele nos lembra, no entanto, que o fenômeno do valor é puramente social e a analogia não é perfeita:

Aqui termina, entretanto, a analogia. O ferro representa na expressão de peso do pão de açúcar uma propriedade natural comum a ambos os corpos, seu peso, enquanto o casaco representa na expressão de valor do linho uma propriedade sobrenatural a ambas as coisas: seu valor, algo puramente social (MARX, 1996, p. 185; MEW 23, p. $71)$.

Em outras palavras, o valor não diz respeito a uma propriedade naturalmente intrínseca às coisas e sim ao modo como se integram socialmente as diversas atividades produtivas humanas, os diferentes trabalhos dentro de uma comunidade. $\mathrm{O}$ fato dessa integração sócio-produtiva se expressar por meio da abstração e através de coisas que passam a possuir um valor - isto é, de modo coisificado ou reificado - é uma característica sui generis do modo de produção mercantil-capitalista. Neste modo de produção, a socialização se dá por via indireta, através da troca de produtos (donde a importância sócio-integrativa das “coisas"). É na medida em que, além de serem úteis, tais produtos exercem esse papel social de integração na divisão social do trabalho, que eles contêm valor (além de valor de uso) e se tornam mercadorias (valor de uso + valor). Por isso que esse duplo caráter das mercadorias é tão central na exposição inicial do Capital; sem tal duplo caráter, que aparece como uma duplicidade ontológica ou de modo de ser, a sociabilidade mercantil-capitalista se tornaria impensável. Marx tem o mérito de desnudar tal estrutura complexa.

O que torna difícil, talvez, a compreensão desse ponto é a maneira pela qual o próprio Marx constrói sua análise no primeiro capítulo do Capital. Como Bidet relembra:

Marx pôde falar da mercadoria sem jamais parecer estar falando do mercado; agora, ele faz como se pudéssemos tratar desta relação social sem mencionar os agentes. Do 
que, no entanto, ele fala na realidade? Se a mercadoria é, como ele dirá, "coisa social", ela se define a partir de uma estrutura de práticas integradas, analisáveis enquanto atividades dotadas de sentido (BIDET, 2004, p. 72-3) ${ }^{6}$.

É, portanto, a determinação desse ponto de vista prático dos agentes, dessa prática social mercantil-capitalista (incluindo seus aspectos fenomenológicos-fetichizantes), que constitui o real objeto de Marx no início do Capital. No entanto, a constituição plena e efetiva dessa prática não se dá sem o estabelecimento da forma-dinheiro. Por isso Marx se dedica à explicação da gênese dessa forma. Retomemos seu raciocínio.

\section{O segredo do dinheiro}

A oposição (Gegensatz) interna entre valor de uso e valor "incrustada" na mercadoria é expressa por uma oposição externa que é estabelecida em uma relação entre duas mercadorias, cuja forma-relativa vale apenas como valor de uso e a forma-equivalente, na qual o valor é expresso, vale apenas como valor de troca. Em outras palavras, o valor de uma mercadoria é expresso de forma autônoma justamente por meio de sua manifestação ou expressão enquanto valor de troca. Certamente, a rigor, mercadoria é valor de uso, ou objeto de uso, e valor, mas ela somente se apresenta como essa entidade dupla quando seu valor tem uma forma de manifestação ou de aparição própria, distinta de sua forma natural, que é a forma do valor de troca. Percebe-se que ela nunca possui essa forma se for considerada isoladamente, mas apenas quando posta em relação de troca com uma segunda mercadoria, de um tipo diferente.

Mas, e quanto à forma-dinheiro, qual sua origem? Esta se encontra na categoria de equivalente universal. $\mathrm{O}$ equivalente universal corresponde à mercadoria equivalente que é excluída da forma-relativa geral, por exemplo o ouro. Seu valor deixa de se expressar no valor de uso das outras mercadorias, até porque o seu próprio valor de uso passa a consistir em expressar o valor de todas as outras mercadorias. Sua própria forma natural é a figura do valor comum a este mundo; o ouro é imediatamente trocável com todas as outras mercadorias. Sua forma corpórea é considerada como a própria "encarnação visível (sichtbare Inkarnation), crisálida social geral de todo trabalho humano" (MARX, 1996, p. 193; MEW 23, p. 81).

Assim, a forma-equivalente geral, em que se consolida a forma-dinheiro, é o modo mais adequado de expressar a generalidade, o caráter abstrato, da forma e da magnitude do valor. Pois até então tínhamos uma certa contradição ao querer expressar o valor, algo

\footnotetext{
${ }^{6}$ Para uma discussão desta escolha estratégica de Marx, veja os parágrafos que seguem esta passagem supracitada.
} 
ontologicamente abstrato, através de mercadorias especificas, dotadas de propriedades particulares. A universalidade do valor não se encontrava manifesta na forma-valor. Nos Grundrisse, Marx declara que:

\begin{abstract}
Essa contradição só pode ser resolvida na medida em que ela própria é objetivada; i.e., na medida em que a mercadoria é posta duplamente, uma vez em sua forma natural imediata, depois em sua forma mediada, como dinheiro. Essa última operação só é possível porque uma mercadoria particular devém, por assim dizer, a substância universal dos valores de troca (...) O dinheiro é o tempo de trabalho como objeto universal, ou a objetivação do tempo de trabalho universal, o tempo de trabalho como mercadoria universal (MARX, 2011, p. 173; MEGA II/1.1, p. 99).
\end{abstract}

O dinheiro torna-se assim o operador prático e visível das operações de abstração relacionadas à troca:

\begin{abstract}
A todo instante, no cálculo, na contabilidade etc., transformamos as mercadorias em signos de valor, as fixamos como simples valores de troca, abstraindo de sua matéria e de todas as suas propriedades naturais. No papel, na cabeça, essa metamorfose procede por simples abstração; mas na troca efetiva é necessária uma mediação efetiva, um meio, para implementar essa abstração (MARX, 2011, p. 136; MEGA II/1.1, p. 77).
\end{abstract}

Deve-se insistir, no entanto, que não é o dinheiro que torna as mercadorias comensuráveis, mas o inverso. É porque as mercadorias enquanto valores são "gelatinas de trabalho humano" e, portanto, comensuráveis entre si, que elas podem expressar todas juntas seus valores em uma mercadoria especial e transformá-la em dinheiro. O dinheiro é a forma de aparição necessária (Erscheinungsform) da medida do valor das mercadorias, isto é, do tempo de trabalho (abstrato). Todas as propriedades da mercadoria enquanto valor aparecem, no dinheiro, na forma de um objeto diferente dela, como uma forma de existência social (ainda que física ${ }^{7}$ ) separada de sua forma natural de existência; eis de volta a nossa duplicidade ontológica.

O dinheiro é assim a materialização do imaterial e do social, a concretização do abstrato. E por que esse abstrato tem de se concretizar e esse social-imaterial tem de se materializar em uma "coisa' como o dinheiro? Primeiro porque, no capitalismo, o abstrato representa a própria integração social, que só se realiza de modo indireto e "pelas costas" dos indivíduos

\footnotetext{
${ }^{7}$ Roman Roldolsky explica o seguinte: "Isso só pode contudo ocorrer na relação entre mercadoria e mercadoria, uma vez que os proprietários de mercadorias não estão em algum tipo de associação comunitária enquanto produtores, mas só podem se relacionar uns com os outros por meio de seus produtos. Consequentemente, a única coisa que pode se tornar a expressão do valor de uma mercadoria é outra mercadoria (da mesma forma, o peso de um pão de açúcar só pode ser expresso pelo peso de outro sólido, por exemplo, o ferro). Portanto, não é suficiente para a mercadoria 'possuir uma existência dupla [meramente] na cabeça'. Essa duplicação em ideia prossegue (e deve prosseguir) até o ponto em que a mercadoria aparece como dupla na troca real; como um produto natural de um lado, como valor de troca do outro. Isto é, o valor de troca da mercadoria obtém uma existência material separada da mercadoria, isto é, alcança independência na forma de dinheiro" (ROSDOLSKY, 1977., p. 112-3).
} 
formalmente independentes. E se o social se realiza de modo essencialmente alienado, devemos adicionar que ele se expressa, como vimos, por meios de coisas, de mercadorias, que aparecem como dotadas de propriedades puramente sociais e supra-sensíveis, como o próprio valor - esse é o sentido do que Marx chama de fetichismo da mercadoria:

\begin{abstract}
Objetos de uso se tornam mercadorias apenas por serem produtos de trabalhos privados, exercidos independentemente uns dos outros. O complexo desses trabalhos privados forma o trabalho social total. Como os produtores somente entram em contato social mediante a troca de seus produtos de trabalho, as caracteristicas especificamente sociais de seus trabalhos privados só aparecem dentro dessa troca. Em outras palavras, os trabalhos privados só atuam, de fato, como membros do trabalho social total por meio das relações que a troca estabelece entre os produtos do trabalho e, por meio dos mesmos, entre os produtores. Por isso, aos últimos aparecem as relações sociais entre seus trabalhos privados como o que são, isto é, não como relações diretamente sociais entre pessoas em seus próprios trabalhos, senão como relações reificadas (sachliche) entre as pessoas e relações sociais entre as coisas (MARX, 1996, p. 199; MEW 23, p. 87. Grifo nosso).
\end{abstract}

O dinheiro representa justamente a universalização dessa coisificação e reificação da síntese social que ${ }_{2}$ por se dar de modo indireto, impessoal, alienado e coisificado, se impõe aos produtores/trocadores enquanto algo que lhes é exterior. Aquilo que tais agentes sociais criaram por meio de suas atividades produtivas se autonomiza e os domina. Outras sociabilidades são possíveis, mas a abstração real (isto é, dotada de efetividade social) e materializada na formadinheiro é uma característica da sociabilidade mercantil-capitalista. Eis o significado do fenômeno do fetichismo do dinheiro em relação ao fetichismo da mercadoria:

\begin{abstract}
A conduta meramente atomística dos homens em seu processo de produção social e, portanto, a figura reificada de suas próprias condições de produção, que é independente de seu controle e de sua ação consciente individual, se manifestam inicialmente no fato de que seus produtos de trabalho assumem em geral a forma mercadoria. $\mathrm{O}$ enigma do fetiche do dinheiro é, portanto, apenas o enigma do fetiche da mercadoria, tornado visível e ofuscante (MARX, 1996, p. 217; MEW 23, p. 107$8)$.
\end{abstract}

O fetichismo é uma ilusão socialmente necessária, um modo de aparecer fundado em um determinado modo de ser social. Acabamos de ver que o dinheiro é um operador prático das operações de abstração. Alguém como Christian Lotz, nas trilhas de Alfred Sohn-Rethel, chega mesmo a afirmar que o dinheiro, na análise marxiana, opera ao modo do esquema categorial kantiano, tal como este é apresentado na Crítica da Razão pura. Ele é uma estrutura social que condiciona o modo como as coisas "aparecem para nós" enquanto sujeitos socializados dentro do modo de produção mercantil-capitalista: 


\begin{abstract}
Marx transfere essa estrutura da primeira Critica kantiana para uma estrutura materialista dentro da qual o dinheiro é determinado como coisidade (thinghood), já que ele determina o quadro sob o qual os indivíduos podem estabelecer e se referir a entidades. Como o dinheiro permanece como a única coisa que existe de forma independente em todas essas trocas, ela se estabelece como a "força transcendental" por trás de tudo, mesmo se Marx já não conceba isso como uma estrutura universal da razão, mas sim como uma forma social historicamente determinada. A formadinheiro é aqui o esquema geral que controla e enquadra todos os relacionamentos e todas as referências a objetos em uma totalidade social (LOTZ, 2014, p. 83).
\end{abstract}

O dinheiro não é aqui uma entidade "fixa"; podemos ver que o dinheiro não é uma coisa (papel, símbolos, etc.). Com efeito, o dinheiro é uma forma social que rege o modo como os indivíduos podem ser ligados uns ao outros e, ao fazê-lo, adquire uma "força transcendental" que molda fenomenologicamente a realidade e determina o que é significativamente acessível na sociedade.

As mercadorias não são, portanto, objetos ontologicamente fixos, como as árvores ou as obras de arte (que podem tornar-se mercadorias); na realidade, o que queremos dizer quando nos referimos a mercadorias é uma forma. No entanto, a forma em que essas coisas aparecem como mercadorias permanece oculta e precisa de exposição. Isto é, encontrar "objetos" no capitalismo significa, portanto, encontrá-los de forma esquematizada, nomeadamente como mercadorias. Na verdade, a própria forma da mercadoria depende da forma-dinheiro. Portanto, o que realmente encontramos através do esquema é a forma social através da qual as entidades se tornam acessíveis a nós no capitalismo. O dinheiro é o operador prático que condiciona aquele modo de apreensão abstrato das coisas que é necessário para as operações cotidianas de troca de mercadorias. O dinheiro é o que nos permite, na vida prática e de modo inconsciente, apreender certas coisas como mercadorias dotadas de valor, e não apenas de valor de uso. Ou seja, o dinheiro é o que estabiliza na realidade social capitalista aquela duplicidade ontológica com a qual Marx inicia o primeiro capítulo do Capital.

\title{
6. Modo de ser e modo de aparecer
}

Com isso, para concluir, podemos retornar ao enigma ontológico que nos serviu de ponto de partida: como uma coisa pode aparecer de dois modos distintos ainda que relacionados, como algo concreto (valor de uso) e como algo abstrato (valor)? O enigma ontológico se esclarece quando nos damos conta de que, para além de um modo de ser material e sensível, que diz respeito ao que Marx chama de propriedades naturais das mercadorias enquanto valores de uso, temos um modo de ser social dessas mercadorias, que são apreendidas 
pelos indivíduos socializados no capitalismo enquanto valores e como dotadas de propriedades ontológicas abstratas. $\mathrm{O}$ modo de ser abstrato das mercadorias se mostra assim como estando enquadrado em uma determinada "fenomenologia" socialmente determinada pelo modo de produção mercantil-capitalista. O dinheiro representa o operador prático desse modo socialmente determinado de percepção das coisas enquanto valores. No Capital, para além das propriedades materiais e sensíveis das mercadorias, devemos ressaltar que a ontologia (abstrata) reside nas práticas sociais marcadas pelas operações de abstração e na própria função social de integração que as mercadorias desempenham no capitalismo. Reprodução material e reprodução social se realizam ambas por meio das coisas, donde o duplo caráter da mercadoria.

Mas, então, por que Marx inicia $O$ Capital com uma linguagem ontológica particular? Por que não falar diretamente de um modo de apreensão, de uma fenomenologia, de uma prática social? Talvez o motivo principal seja o de que Marx quis retratar a realidade do fetichismo e da reificação, o fato de que a sociabilidade mercantil-capitalista e seus atributos abstratos se expressam pelas próprias coisas. Assim, uma sociabilidade indireta e abstrata precisa se expressar em coisas materiais, às quais, enquanto mercadorias, passamos a atribuir inconscientemente $^{8}$, de modo socialmente efetivo e objetivo, propriedades igualmente abstratas - estas últimas devem portanto passar da mera representação mental e se "encarnar" em "coisas sociais" (FAUSTO, 1987, p. 105). Somos nós mesmos, nossas próprias práticas sociais, e não Marx, que criamos esse qüiproquó ontológico que ele pretende descrever, mostrar a gênese sócio-histórica e explicitar o seu caráter absurdo ou mesmo louco ${ }^{9}$ no começo de sua obra prima. Desde o começo, Marx procurou, ao mostrá-la sob a luz de sua pena, ressaltar o caráter excepcional da mercadoria, sua natureza "fisicamente metafísica" criada pelo fetichismo cotidiano que marca nossas relações sociais no capitalismo.

\footnotetext{
${ }^{8}$ Não é demais insistir que tal atribuição é essencialmente prática: "Portanto, os homens relacionam entre si seus produtos de trabalho como valores não porque consideram essas coisas meros envoltórios materiais de trabalho humano da mesma espécie. Ao contrário. Ao equiparar seus produtos de diferentes espécies na troca, como valores, equiparam seus diferentes trabalhos como trabalho humano. Não o sabem, mas o fazem" (MARX 1996, p. 200).

9 "Quando eu digo casaco, botas etc. se relacionam ao linho como a corporificação geral de trabalho humano abstrato, salta aos olhos a loucura (Verrücktheit) dessa expressão. Mas quando os produtores de casaco, botas etc. relacionam essas mercadorias ao linho - ou ao ouro e à prata, que em nada muda a coisa - como equivalente geral, a relação dos seus trabalhos privados com o trabalho social total lhes aparece exatamente nessa forma louca" (MARX, 1996, p. 201; MEW 23, p. 90. Tradução modificada).
} 


\section{REFERÊNCIAS BIBLIOGRÁFICAS}

ALTHUSSER, L. Posições 2. Rio de Janeiro: Graal, 1980.

BIDET J., Explication et reconstruction du Capital, Paris: PUF, 2004.

ENGELS, F.; MARX, K., Marx-Engels-Werke, 42 volumes. Berlim: Dietz, 1952-2013. [Citado como MEW e número do volume.]

ENGELS, F.; MARX, K., Marx-Engels-Gesamtausgabe. Berlim: Akademie, 1972-. [Citado como MEGA e o número do volume.]

FAUSTO, R., Marx: Lógica e Politica, Tomo 1, $2^{\mathrm{e}}$ éd., Sao Paulo: Brasiliense, 1987.

HARVEY D., A Companion to Marx's Capital, London; New York : Verso, 2010.

LOTZ, C. The Capitalist Schema: Time, Money, and the Culture of Abstraction. New York: Lexington Books, 2014.

MARX, K. O capital - Livro I - Capítulo VI (Inédito). São Paulo: Ciências Humanas, 1978.

Para a Crítica da Economia Política. Tradução de Edgard Malagodi; in : Os Pensadores. São Paulo: Abril Cultural, 1985.

O Capital: Crítica da Economia Política. Tradução de Regis Barbosa e Flávio R. Kothe. Os Economistas. São Paulo:Abril Cultural, 1996.

. Grundrisse: Manuscritos Econômicos de 1857-1858, São Paulo: Boitempo, 2011

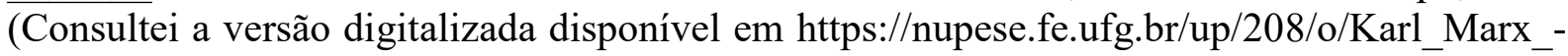
_Grundrisse_(boitempo)_completo.pdf). Consulta em 01/10/2018.

POSTONE, M. Time, Labor, and Social Domination: A Reinterpretation of Marx's Critical Theory. Cambridge; New York: Cambridge University Press, 2003.

RANCIÈRE J., Le concept de critique et la critique de l'économie politique des Manuscrits de 1844 au Capital. In: ALTHUSSER, L. (org.), Lire Le Capital, 3e éd., Paris: PUF, 2014.

ROSDOLSKY, R., Making of Marx's Capital, 1St Edition, London: Pluto Press, 1977. 